\title{
Erratum to: Effectiveness of rehabilitation treatments on a slowly revegetating hillslope in a recently burned coastal forest, Republic of Korea
}

\author{
Chang Woo Lee $\cdot$ Jung Il Seo $\cdot$ Ho Joong Youn • \\ Kyongha Kim
}

Published online: 14 December 2013

(c) International Consortium of Landscape and Ecological Engineering and Springer Japan 2013

\section{Erratum to: Landscape Ecol Eng}

\section{DOI 10.1007/s11355-013-0218-7}

In the original publication, the corresponding author's present address was published incorrectly. The correct affiliation should appear as in this article.

The online version of the original article can be found under doi:10.1007/s11355-013-0218-7.

\section{W. Lee $\cdot$ H. J. Youn $\cdot$ K. Kim}

Division of Forest Disaster Management, Department of Forest Conservation, Korea Forest Research Institute,

207 Cheongnyangni 2-dong, Dondaemoongu,

Seoul 130-712, Republic of Korea

\section{J. I. Seo}

College of Earth, Ocean, and Atmospheric Sciences,

Oregon State University, 104 CEOAS Building,

Corvallis, OR 97331-5503, USA

Present Address:

J. I. Seo (ه)

Department of Forest Resources, College of Industrial Sciences,

Kongju National University, 54 Deahakro, Yesaneup, Yesangun, Chungcheongnamdo 340-702, Republic of Korea

e-mail: jiseo.watershed@gmail.com 